\title{
Gêneses do gênero road movie ${ }^{1}$
}

\author{
IIIIIIIIIIIIIII Samuel Paiva
}

1. Artigo apresentado no Grupo de Pesquisa em Cinema, do XXXIII Congresso Brasileiro de Ciências da Comunicação, em setembro de 2010.

2. Professor adjunto do Departamento de Artes e Comunicação e do Programa de Pós-Graduação em Imagem e Som da Universidade Federal de São Carlos. E-mail: sampaiva@uol.com.br 
Resumo

Este trabalho tem interesse em problematizar prováveis gêneses do road movie, considerando aspectos históricos relacionados às origens tanto dos gêneros cinematográficos, de uma maneira mais abrangente, quanto do filme de estrada, mais especificamente. Nesse sentido, apresenta uma reflexão resultante da comparação de textos produzidos por diversos autores, pesquisadores e diretores de cinema, que têm investido sobre o road movie em suas produções, destacando-se, entre outras, realizações do Brasil.

\section{Palavras-chave}

história, gênero cinematográfico, road movie

Abstract

This work is interested in questioning probable genesis of the road movie genre, considering historical aspects related to the origins of film genres, in a broader sense, as much as to the road movies specifically. In this sense, it is a reflection that results from the comparison of texts by various authors, researchers and filmmakers, who have invested in the road movie in their productions, especially, among others, achievements from Brazil.

\section{Key-words}

history, genre, road movie 


\section{Início do percurso}

Quando nasceram os filmes de estrada? Em Homero, no desejo de Ulysses retornar à casa? Nos primeiros documentários de cineastas-viajantes como Robert Flaherty? Na influência dos fotógrafos humanistas que, como Cartier-Bresson, cruzaram fronteiras para entender como viviam os outros, aqueles que não faziam parte de sua própria cultura? (SALLES, 2005).

E responde Walter Salles às indagações que ele mesmo se coloca: "Provavelmente, em todas essas origens". Porque os filmes de estrada estão relacionados a dimensões intrínsecas do ser humano, como o nomadismo, a capacidade de locomoção e o interesse nela por razões ou necessidades distintas. É instigante o fato de tal afirmação sobre o road movie nos fazer pensar nesse gênero como sendo bastante antigo, existindo muito antes do cinematógrafo e de veículos automotores, como trens e carros, remetendo-se à Antiguidade Clássica, às viagens de Ulysses ou Odisseu, na Odisseia, de Homero (2006). Inclusive porque a própria noção de gênero, como algo que diz respeito à classificação das obras artísticas, de fato vem da Antiguidade Clássica: "A classificação de obras literárias segundo gêneros tem a sua raiz na República de Platão", afirma Anatol Rosenfeld (1997, p. 15). Sócrates já mencionava três tipos de obra poética: as que são inteiramente imitação (tragédia e comédia, por exemplo), as que são simples relatos do poeta (o que viria a se constituir como o gênero lírico), as que unem ambas as coisas, imitação e relatos (como é o 
caso das epopeias). A noção da arte como imitação será reforçada na Poética, de Aristóteles (2000). Seu empenho em classificar, categorizar, esmiuçar as partes constituintes da tragédia, tratando de compreendê-la em termos de uma espécie de fórmula repetível, segundo regras bem definidas para sua concepção e execução cênica, leva-nos a pensar no gênero como uma repetição com diferença, o que afinal continua valendo até os dias de hoje. Entretanto, se já nos estudos literários a teoria dos três gêneros - épico, lírico, dramático - não constituía um sistema puro, sem contágios, tampouco no cinema isso viria a ocorrer. Notemos, a propósito, que a teoria do cinema obtém dos estudos literários muito de sua fundamentação sobre os gêneros. Eis um exemplo emblemático dessas conexões: no campo da literatura, Anatol Rosenfeld fala no "significado substantivo do gênero":

A teoria dos gêneros é complicada pelo fato de os termos "lírico", "épico" e "dramático" serem empregados em duas acepções diversas. A primeira acepção - mais de perto associada à estrutura dos gêneros poderia ser chamada de "substantiva". Para distinguir essa acepção da outra, é útil forçar um pouco a língua e estabelecer que o gênero lírico coincide com o substantivo "A Lírica", o épico com o substantivo "A Épica" e o dramático com o substantivo "A Dramática" (1997, p. 17).

No campo do cinema, ocorre algo muito próximo. Prova disso pode ser a proposição de Rick Altman (2000), muito parecida com a de Rosenfeld, sobre os gêneros "substantivos" e "adjetivos" no âmbito cinematográfico. Pensando nos musicais hollywoodianos dos anos 1920 e 1930, mais precisamente na transição do cinema silencioso para o sonoro, Altman afirma que, naquele momento, o termo musical era compreendido mais como um adjetivo de substantivos já então consolidados, como a comédia. Daí, foi possível surgir uma noção como a de comédia musical, um substantivo seguido de um adjetivo. A consolidação do musical como substantivo só iria ocorrer posteriormente. De fato, há vários postulados propostos por Altman - inclusive relacionados a essas dimensões adjetivas e substantivas - que se aplicam a diferentes gêneros cinematográficos, compreendidos em uma ampla perspectiva. Até porque, como afirma esse teórico e historiador, os gêneros não têm identidades e fronteiras estáveis. São frequentemente híbridos, trans-históricos, 
não seguem evoluções predizíveis, ainda que sua natureza repetitiva muitas vezes possa nos levar a pensar dessa maneira. Os gêneros propõem recorrentemente intertextualidades. Funcionam com uma lógica simbólica simples, capaz de abranger diferentes sujeitos em contextos distintos. Podem ter funções rituais ou ideológicas, envolvendo-se com as sociedades, as culturas e seus valores. Tudo isso funciona como premissa para quem pretende conhecer os gêneros cinematográficos - inclusive o road movie. Ou seja, quando Walter Salles (2005) diz que "nem todos os filmes de estrada são iguais", está na verdade reiterando uma certa compreensão, considerada no âmbito dos estudos de gênero no cinema, de que não é possível defini-lo de maneira precisa. Há portanto pontos de imprecisão, seja quanto à origem, seja quanto a uma definição do que pode ser considerado um road movie. Isso, contudo, não deve nos impedir de tentar cercar esse gênero, pretendendo em alguma medida conhecer a sua história.

\section{Os filmes de viagem}

O início da história do cinema, se considerado como o advento do cinematógrafo, está fortemente marcado tanto pelas máquinas que passam a colocar as imagens em movimento como pelas máquinas que são capazes de transportar os seres humanos. Como diz Walter Moser (2008, p. 7), “a invenção do automóvel como veículo de locomoção individual e privado com motor à combustão e do cinema como nova mídia capaz de representar o movimento se situa por

3. Tradução do autor, como ocorrerá com outros textos de origem estrangeira. volta do fim do século XIX”. ${ }^{3}$ As invenções do cinema e do automóvel, como afirma Moser, causam um profundo impacto no imaginário coletivo, no que concerne a uma nova concepção do tempo e do espaço, como novos paradigmas da modernidade - no caso, de uma "modernidade sólida", nos termos de Zygmunt Bauman (2001). Na modernidade sólida, o espaço predomina sobre o tempo (diferentemente do que ocorre na "modernidade líquida”, em que o tempo se sobrepõe ao espaço, graças às tecnologias informáticas e afins).

A modernidade sólida tem interesse na conquista do espaço, vinculando-se inclusive a toda uma concepção colonialista de apropriação do lugar do outro. É nessa perspectiva que se construíram vários Estados-nações. Seguindo tal linha de raciocínio, são em boa 
parte previsíveis as razões que farão vários estudos sobre o road movie apontarem o western como seu precursor, uma vez que esse gênero está fortemente associado à apropriação do espaço, no caso, nos Estados Unidos, onde “a conquista do Oeste” é um ícone do poder da dominação da cultura wasp sobre as demais - por exemplo, sobre a cultura indígena. Antes, porém, de considerar essa questão, convém refletirmos um pouco mais sobre a associação entre meios de transporte e cinema ou, como propõe Moser, sobre uma concepção de modernidade associada ao deslocamento, seja pela "locomoção" (locomotion), relacionada ao deslocamento físico propriamente, que pode se dar por meios de transporte - como automóvel, trem, barco, avião —, seja pela "midiamoção" (médiamotion):

A midiamoção é uma forma de mobilidade que as mídias nos oferecem,
mas que, num certo sentido, substitui ou redobra o deslocamento físi-
co, oferecendo aos seres humanos uma experiência quase paradoxal: o
contato a distância. A midiamoção permite o mover-se, o encontrar-se
em outro lugar, mas sem o deslocamento físico (MOSER, 2008, p. 9).

A midiamoção na transição entre os séculos XIX e XX, obviamente, era bem distinta da que se verifica na transição do século XX para o XXI. No primeiro momento, a fotografia e o cinema eram as mídias por meio das quais as populações, sobretudo dos centros urbanos, podiam satisfazer sua curiosidade em relação a lugares distantes e exóticos do planeta. Em tal contexto, um dos primeiros gêneros do cinema a ganhar força é justamente o filme de viagem ou o travelogue. Em sua tese sobre "filmes de viagem [travelogues] e a atração do exótico (189o-1920)", Jennifer Peterson (1998) reconhece o cinema do período em questão como uma mídia entre outras - o vaudeville, os espetáculos de lanterna mágica, as feiras mundiais, por exemplo - e destaca a relevância da não ficção para a compreensão da produção e da recepção cinematográfica no período. No âmbito da não ficção, como ela diz, vários podiam ser os temas, os assuntos tratados, entretanto:

de todos os diversos tópicos tratados pelo cinema de não ficção, imagens de viagem e terras estrangeiras eram de longe as mais numerosas. Muitas das primeiras imagens em movimento até então jamais projetadas podem ser consideradas como filmes de viagem (p. 2). 
A propósito, filmes dos irmãos Lumière são exemplos citados. E, de fato, pensando na conexão entre cinema, viagem e meios de transporte, é relevante lembrar aquela que é tida como a primeira sessão de cinema, com a exibição da A chegada do trem à estação de Ciotat (1895), justamente dos irmãos Lumière.

Como Tom Gunning (1995) diz, referindo-se a esse momento do cinema dos primeiros tempos, a viagem se tornou um meio de apropriação do mundo pelas imagens. Na verdade, Gunning, assim como Jennifer Peterson, refere-se a toda uma variedade de mídias que, mesmo antes do cinematógrafo, já trabalhavam com a simulação de viagens em dispositivos diversos. Se contudo esses autores, Peterson e Gunning, estão voltados à pesquisa sobre a não ficção, Charles Musser (1990) vai se interessar sobre a maneira como travelogues e filmes afins influenciarão a produção ficcional. Musser destaca, por exemplo, trabalhos de Edwin S. Porter, realizados no intervalo de 1903-1904, procurando observar como algumas de suas ficções têm origem em registros documentais anteriores, que incluíam também cenas de viagem.

De fato, há toda uma produção ficcional, inclusive desses primórdios do cinema, relacionada à ideia de viagem. Viagem à lua (1902), de Georges Méliès, um filme de ficção científica, de viagem ao espaço, pode ser lembrado como um exemplo emblemático. A história dos terrestres que, em uma nave espacial, chegam à Lua, de onde retornam depois de serem perseguidos por ETs, é um marco da conexão locomoção-máquina-cinema, tão explorada até os dias de hoje.

Portanto, dado esse quadro até então esboçado, cabe aqui um ponto de inflexão. A viagem, se pode ser considerada como um dado precursor do que hoje convencionamos chamar de road movie, está relacionada historicamente tanto ao campo do documentário como ao da ficção, podendo, em alguns casos, reunir ambos. Não é o caso, neste momento, de seguirmos com uma reflexão aprofundada acerca do que constitui um documentário ou uma ficção. Mas, apenas como baliza ao enfrentamento do problema, convém lembrar Roger Odin (1984), quando ele menciona o campo da ficção (com seus vários gêneros: melodrama, policial, terror etc.) e o campo do documentário (também com os seus vários gêneros: biográfico, científico, etnográfico etc.). Ou seja, os dois campos - ficção e documentário - têm os seus próprios gêneros. E em se tratando de filmes de estrada, vale notar, a imbricação dos dois campos poderá ser 
recorrente, o que pode ser confirmado por depoimentos de cineastas como Walter Salles ou por filmes como Viajo porque preciso, volto porque te amo (2009), de Marcelo Gomes e Karim Aïnouz, que, tendo se iniciado como um projeto de documentário, acabou resultando em uma ficção (questão à qual retornaremos mais adiante).

\section{Westerns, gangsters, filmes noir}

Apesar das possibilidades de hibridações inerentes aos gêneros, de seus momentos mais ou menos adjetivos ou substantivos, para os pesquisadores do assunto, sempre haverá a necessidade de definir o seu objeto. Tendo isso em vista, cabe lembrar Timothy Corrigan, quando ele propõe o seguinte: "road movies são, por definição, filmes sobre carros, caminhões, motocicletas ou algum outro descendente motorizado do trem do século XIX" (apud COHAN \& HARK, 1997, p. 3). Os trens são inclusive um dos meios através do qual podemos encontrar vínculos do road movie com o western. Stephanie Watson (1999) discute a questão partindo do pressuposto de que o western é o "progenitor" do filme de estrada e de outros gêneros tidos como de origem norte-americana. Isso porque histórias que podem ser consideradas propriamente com características de western surgem, como confirma a autora, no início do século XIX e seguem daí por diante acompanhando a história dos Estados Unidos. Progressivamente, as narrativas do western passam a se relacionar de forma mais evidente com o caminho de migração para o Oeste, com suas oportunidades de ganhos vinculados a ouro e prata, gado etc. Nesse caminho, ferrovias são construídas, inclusive com investimento do Estado, instituição responsável pela promoção da ordem civilizatória. Em tal contexto, tem relevância considerável a questão da lei. Watson, a propósito, observa que muitos westerns exploram a tensão entre, por um lado, um outsider que se desloca e que é capaz de impor uma ordem moral própria, mas sem obedecer à autoridade federal e, por outro lado, a comunidade embrionária aliada à civilização (1999, p. 23). Eis aqui outro ponto instigante para pensarmos em termos dos vínculos dos road movies com os westerns: suas narrativas de busca e protagonistas que se deslocam com a tensão de estar dentro ou fora da lei. 
Mas os protagonistas do western, mesmo quando são fora da lei, acabam quase sempre reiterando o estabelecimento da suposta civilização, com sua apropriação do território e o estabelecimento da família e da comunidade à sua volta. Já nos road movies, a busca que provoca o deslocamento vincula-se a uma necessidade de liberação, seja do espaço familiar, seja do espaço do trabalho regular capaz de promover o bem-estar do indivíduo em sociedade, segundo a lógica capitalista de acúmulo de propriedades materiais. O road movie inscreve-se no âmbito de representação da modernidade, com suas tecnologias, porém, explicitando crises e contradições. Eis aí uma das prováveis razões para que um pesquisador como David Laderman (2002) entenda o gênero em questão a partir do que ele observa como sendo uma dialética envolvendo valores conservadores e desejos de rebelião, o que faz com que o road movie consiga pôr em xeque os mitos associados ao indivíduo e à sociedade norte-americana.

Mas não só o western poderia ser analisado no âmbito dos precursores do road movie. Alguns dos pesquisadores do assunto, embora em geral tenham Hollywood como paradigma essencial da história do gênero cujas gêneses aqui problematizamos, reconhecem a possibilidade de relacioná-lo, por exemplo, ao filme noir ou a outros gêneros que possam ser associados à angústia existencial da Grande Depressão ou da Segunda Guerra Mundial. Títulos como As vinhas da ira (The grapes of wrath, John Ford, 1940), Curva do destino (Detour, Edgar G. Ulmer, 1945) e Amarga esperança (They live by night, Nicholas Ray, 1949) poderiam ser lembrados, nesse sentido, como exemplos. Steve Cohan e Ina Rae Hark (1997, p. 6-7) apontam que alguns desses precursores, mesmo quando lidando em alguma medida com a ideia de revolta, por vezes acabam reforçando os valores da cultura dominante, como é o caso de Aconteceu naquela noite (It happened one night, Frank Capra, 1934), filme no qual a milionária Ellie Andrews (interpretada por Claudette Colbert) foge do casamento programado por seu pai e se encontra na estrada com o jornalista Peter Warne (Clarke Glabe), por quem ela vai se apaixonar e com quem, ao final, se casa, com a benção paterna. Ou seja, nesse caso, a estrada não tem dimensão de perigo ou ameaça. Pelo contrário, apresenta uma perspectiva conciliadora. Cohan e Hark, de fato, afirmam:

romance e restabelecimento do consenso democrático dominam a estrada em filmes de Hollywood dos anos 1930 e 1940, como Love on 
the run [W.S van Dyke, 1936], Fugitive lovers [Richard Boleslawski, 1934], Sullivan's travels [Preston Sturges,1941], Saboteur [Sabotador, Alfred Hitchcock, 1942] e Without reservations [Mervyn LeRoy, 1946], assim como ocorre na comédia de Frank Capra (1997, p. 6).

Essas considerações nos fazem recordar novamente Rick Altman (2000) quando ele, questionando a origem dos gêneros, observa que, em seu início, um gênero parece incorporar de forma aparentemente fortuita distintos gêneros desvinculados entre si. Notemos a propósito que, por exemplo, Aconteceu naquela noite é muitas vezes considerado como uma comédia. Ou seja, com esses filmes precursores do road movie, estamos provavelmente no âmbito da dimensão “adjetiva” do gênero, segundo os critérios já apresentados anteriormente, de Anatol Rosenfeld e do próprio Altman.

Quando começaria então o caráter substantivo do road movie? No contexto norte-americano, parece haver um consenso: com o surgimento de On the road, o romance de Jack Kerouac (lançado em 1957). O livro é um ponto de inflexão, ao assumir um caráter mais contestador da cultura dominante. E, nesse sentido, passa a se constituir como uma referência de rebelião, logo levada ao cinema e incorporada em personagens como aqueles interpretados por James Dean, entre tantos outros rebeldes que têm sua performance contestadora associada ao automóvel. O caráter substantivo do road movie passa a se confirmar nesse momento, deixando para trás a conciliação característica de filmes como Aconteceu naquela noite, entre outros que poderiam ser considerados como característicos da fase adjetiva do gênero. Em lugar da conformidade com o status quo, surgem, na fase substantiva, contestadores como Bonnie and Clyde (Arthur Penn, 1967) e Easy rider (Dennis Hopper, 1969), considerados frequentemente, no contexto norte-americano, marcos inaugurais do gênero em questão. Contudo, convém aqui não perdermos de vista os argumentos de David Laderman e sua dialética da conformação e da rebelião. A propósito, também Steve Cohan e Ina Rae Hark, quando discutem On the road, o romance de Kerouac, observam como o personagem Sal Paradise está integrado num certo establishment, já que sua fuga é só um intervalo da vida familiar e universitária, para a qual ele vai retornar ao final de um ciclo de viagens, em contraposição ao que ocorre com Dean Moriarty, esse sim um sujeito sem vínculos, a não ser com a própria estrada. Feita 
a ressalva, entretanto, é bastante forte a evidência de um caráter contestador da ordem dominante em road movies desse momento (substantivo) em diante.

\section{Filme de estrada no Brasil}

Uma possibilidade metodológica para conhecer as origens de algum gênero pode ser a verificação do que está dado no campo da historiografia sobre o assunto. Tendo isso em vista, é fato que nos Estados Unidos encontramos um considerável grupo de pesquisadores dedicados a compreender os gêneros - o road movie, entre outros - como questão relacionada ora aos textos fílmicos, ora ao público, ora à indústria cinematográfica, ora a todos esses fatores simultaneamente, observados muitas vezes com o visionamento de conjuntos de filmes. Uma das causas para isso talvez esteja relacionada ao fato de que no contexto norte-americano o parâmetro da indústria é tão presente que obriga, de uma certa maneira, a atenção para seus aspectos de produção em grandes escalas.

Em contrapartida, em países como o Brasil, onde a indústria cinematográfica ainda não chegou a existir de fato, apesar de tentativas como as da Cinédia, Vera Cruz, Maristela, Multifilmes, entre outras empresas de intenções industriais, como a mais recente Globo Filmes, o parâmetro industrial - e, consequentemente, os gêneros dele decorrentes, compreendidos em uma chave mais popular - não chega ainda a se constituir como objeto de estudo de maior interesse. De fato, o estudo de gênero, quando existente, no caso do Brasil, parece ter se orientado mais pelo parâmetro da "política dos autores", que, como se sabe, não deixa de considerar a dimensão genérica de autores como Hitchcock ou Nicholas Ray, entre tantos outros diretores hollywoodianos que vão interessar aos críticos da Cahiers du Cinéma e aos realizadores da Nouvelle Vague, propositores da política dos autores. Não por acaso, aliás, os filmes dessa geração têm o gênero como dado, ainda que em um registro paródico, como é o caso das produções de Jean-Luc Godard, realizador de um road movie: Weekend (1967).

De fato, no Brasil, o paradigma autor tem orientado alguns (poucos) estudos que podem ser lembrados como referência para a compreensão do road movie no país. Um desses estudos é o livro 
Caminhos de Kiarostami, de Jean-Claude Bernardet (2004). A uma certa altura dos argumentos, Bernardet faz o "elogio do carro" (p. 39) nos filmes de Kiarostami, estabelecendo conexões com o neorrealismo italiano e Rosselini, especialmente. E segue discutindo a poética do deslocamento; o diálogo íntimo que o interior do carro permite aos passageiros, que conversam sem se olhar, como se estivessem numa sessão de psicanálise; a ampliação do espaço pelos recursos de campo e contracampo e pelas relações nem sempre sincrônicas da imagem com o som; as indeterminações entre a ficção e o documentário etc. De fato, esse livro está interessado sobretudo na obra do realizador iraniano Abbas Kiarostami, em suas recorrências ou matrizes autorais, discutindo aspectos temáticos e formais relacionados às estruturas dos seus filmes, suas vinculações com o carro, as trajetórias, o espaço etc., mas também estabelece a todo instante cotejos com o trabalho de outros realizadores e seus filmes (também autorais): Kiko Goifman, Michael Snow, Hollis Frampton, Jorge Furtado, Suzana Amaral, Sandra Kogut, Marguerite Duras, Michael Klier, Eduardo Coutinho etc. Um dos grandes méritos do livro é justamente a proposta dessa intertextualidade, ou hipertextualidade, como propõe Bernardet. O viés industrial do gênero é desconsiderado, até porque na verdade esse não é um ponto interessante a respeito de Kiarostami e dos demais realizadores cotejados com ele. Mesmo assim, a análise se interessa por agrupamentos de filmes e diretores, de nações diferentes, de contextos diversos, mas percebidos em relação. Tal perspectiva transcultural é coerente com o que o próprio Bernardet (1995) propõe em outro texto de sua autoria - Historiografia clássica do cinema brasileiro -, no qual defende, ao discutir gêneros do cinema silencioso, que eles sejam percebidos em suas dimensões internacionais. Já em seu blog, mais recentemente, ele traz uma ampla entrevista com Marcelo Gomes e Karim Aïnouz, diretores do filme Viajo porque preciso, volto porque te amo (2009). A uma certa altura da entrevista, falando sobre a gênese do filme, que começou com uma pesquisa para um documentário sobre feiras do Nordeste, na chave das "culturas híbridas" (CANCLINI, 1998), Marcelo Gomes afirma: "A coisa primordial é que queríamos viajar pelo sertão", pois "era um lugar que conhecíamos de memórias, conversas de família, é um lugar mítico pra nós cineastas. É o nosso western" (apud BERNARDET, 2010). Depois, o próprio Gomes esclarece que, no transcorrer das filmagens, os dois 
diretores, ele próprio e Karim, foram desconstruindo os clichês que tinham na cabeça em termos de uma idealização do sertão. Algo parecido com isso também ocorre em Cinema, aspirinas e urubus (Marcelo Gomes, 2005), road movie emblemático, em termos da produção cinematográfica contemporânea no Brasil, também em pauta nas entrevistas de Jean-Claude com os referidos cineastas.

Outra referência é o livro lançado pelo jornalista Marcos Strecker (2010), que também deve ser mencionado como um dos marcos da incipiente historiografia do road movie no Brasil. O título - Na estrada, o cinema de Walter Salles - já situa inequivocamente tanto o interesse do autor no gênero em questão quanto o recorte autoral, centrado em um realizador renomado no âmbito do cinema brasileiro e internacional. A uma certa altura, Strecker afirma que a obra de Walter Salles é "uma reafirmação refinada da visão do nosso melhor crítico”, no caso, Paulo Emílio Salles Gomes, quando este diz que "nada nos é estrangeiro, pois tudo o é. A penosa construção de nós mesmos se desenvolve na dialética rarefeita entre o não ser e o ser outro" (apud STRECKER, 2010, p. 22-23). A lembrança é bem pertinente, embora as noções de "ocupante" e "ocupado" na concepção de Paulo Emílio devam ser ajustadas para a compreensão de um cineasta como Walter Salles, que inclusive passa a trabalhar no terreno do "ocupante". Entre outros, estamos nos referindo ao projeto que o diretor brasileiro atualmente desenvolve sobre On the road, o livro de Kerouac cujos direitos de adaptação para o cinema foram adquiridos por Francis Ford Coppola em 1979. Pensando no desafio de Walter Salles, Strecker apresenta uma série de considerações sobre a gênese do projeto literário de Kerouac: situa a influência de escritores como Walt Whitman, Thomas Wolfe, Henry Thoreau, Arthur Rimbaud, Herman Melville, Joseph Conrad e Albert Camus; faz as conexões de Kerouac com a geração beat - Neal Cassady, Allen Ginsberg e William Burroughs, entre outros -; e fala sobre a formação de um estilo orientado pelo fluxo de consciência, pela escrita automática e pela referência ao jazz. Em suma, On the road é observado em várias perspectivas, consideradas inclusive no âmbito da história dos Estados Unidos em sua formação como nação, até o momento de intensificação da Guerra Fria, da escalada do macarthismo e também da gestação dos movimentos pelos direitos civis. A uma certa altura, depois de afirmar que "cinquenta anos separam o romance de Kerouac da versão 
cinematográfica de Walter", pergunta Strecker: "Qual a relação da sociedade atual com aquela que gerou On the road?" (2010, p. 52). E como nos faz perceber o jornalista, para tal pergunta, é difícil encontrar uma resposta direta. Talvez por isso, aliás, algumas tentativas de adaptação de On the road para o cinema não tenham se concretizado, apesar de estarem vinculadas a realizadores notáveis, como Gus Van Sant, o próprio Coppola e Joel Schumacher. Walter Salles, contudo, está atento às dificuldades, tanto que resolveu realizar um documentário - Searching for On the road (2010) como estágio preparatório da adaptação do romance de Kerouac para o cinema.

Sem dúvida, é instigante o fato de tal projeto hoje estar nas mãos de um cineasta brasileiro que tem sido um dos que mais se destacam, no Brasil e no mundo, no campo da produção de filmes de estrada, alguns com ampla repercussão internacional, como é o caso de Terra estrangeira (1995), Central do Brasil (1998) e Diários de motocicleta (2004). Além disso, também é sintomático que, tal como ocorre com Bernardet e seu livro sobre Kiarostami, o texto de Marcos Strecker estabeleça, a todo momento, cotejos entre Walter Salles e outros fotógrafos ou cineastas, como o próprio Kiarostami e também Nelson Pereira dos Santos, Glauber Rocha, Coppola, Orson Welles, Walker Evans, Robert Frank, Nicholas Ray, D. A. Pennebaker, Dennis Hopper, Robert Redford e Daniela Thomas (parceira de Walter Salles em vários projetos), entre muitos outros diretores, produtores, atores, músicos etc. Mas é certamente Wim Wenders a figura de maior destaque nesses cotejos, como comprova o quinto capítulo do livro, intitulado "Walter Salles, Wim Wenders e road movies - Uma conversa e uma aula" (2010, p. 232-255). É quando "mestre e pupilo" (p. 233), Wenders e Salles, respectivamente, num intervalo de um curso ministrado por ambos no Festival de Cinema de Salônica, na Grécia, em novembro de 2006, conversam, mediados por Strecker, sobre suas experiências cinematográficas, especialmente, é claro, sobre os filmes de estrada, com destaque para a relação com os Estados Unidos nos projetos de ambos.

Em suma, para Walter Salles, como afirma Strecker, os filmes de estrada relacionam-se com crises de identidade de personagens que, por sua vez, expressam a crise das próprias culturas nacionais. Além disso, têm a ver com imprevisibilidade, com improvisação, com acompanhamento dos personagens no confronto com a rea- 
lidade (como num documentário), com a verdade da observação, com roteiros que permitem o fugir da rota e ir além,o superar a conformidade com a experimentação, com a apreensão do outro. Em tais perspectivas, são mencionados filmes como Easy rider (Dennis Hopper, 1969), Passageiro, profissão repórter (Michelangelo Antonioni, 1975), Alice nas cidades (Wim Wenders, 1974), Iracema, uma transa amazônica (Jorge Bodanzky, Orlando Senna, 1976) e Dez (Abbas Kiarostami, 2002).

\section{Pesquisas sobre filme de estrada no Brasil}

Além desses dois livros - Caminhos de Kiarostami, de Bernardet, e Na estrada, o cinema de Walter Salles, de Marcos Strecker - , que são publicações marcantes em termos de uma reflexão sobre os filmes de estrada para um público mais abrangente no Brasil, existem também neste país alguns trabalhos acadêmicos (RODRIGUES, 2007; BRANDÃO, 2009; SILVA, 2009), resultantes de projetos de pesquisa, os quais denotam um interesse crescente pelo assunto. Esses estudos, estando mais ou menos pautados pelo paradigma da política dos autores ou do gênero em outra perspectiva além da autoral, também sinalizam um horizonte promissor para a compreensão do filme de estrada como um meio relevante ao questionamento de aspectos relacionados a nacionalidade, economia, sexualidade, classe e etnia - áreas frequentemente observadas em uma perspectiva transcultural ou intercultural.

De fato, no Brasil, ainda existe um universo bastante amplo a ser pesquisado sobre a história do road movie. Para isso, é necessário um levantamento dos filmes, seguido das respectivas análises, de modo a propiciar a percepção, de uma forma mais geral, de um conjunto filmográfico constituinte do corpus dos filmes de estrada nacionais. Levadas em consideração as várias possibilidades de gêneses do gênero, como percebemos até aqui, a tarefa não é fácil e pressupõe a observação de filmes desde o cinema dos primeiros tempos. Nesse sentido, aliás, o período silencioso do cinema brasileiro é rico em possibilidades, ainda que sejam poucos os filmes preservados. Em tal perspectiva, os filmes de Major Reis em que ele acompanha as expedições da Comissão Rondon ao Norte e ao Noroeste do Brasil podem ser lembrados como um bom exemplo. E, além dos natu- 
rais (como então eram conhecidos os documentários), há também a possibilidade de reconhecimento de posados (como então eram conhecidos os filmes de ficção). É o caso dos vários filmes que, sendo inspirados no western ou no policial norte-americano, constituem protofilmes de estrada brasileiros (do Ciclo do Recife, por exemplo, é possível a lembrança de Jurando vingar, dirigido por Ary Severo, 1925). E há também casos de filmes híbridos, entre ficção e documentário, como Novos horizontes (Leopoldis-Film, 1934), um longa-metragem gaúcho, produzido por ocasião da Exposição de São Leopoldo, em 1934, em homenagem à colonização alemã em São Leopoldo e em Novo Hamburgo. Nesse filme, a viagem de um casal (no registro ficcional) vai orientando o enredo, eminentemente associado aos registros documentais da pujança econômica do local e aos supostos responsáveis por ela: políticos, militares, comerciantes, fazendeiros, religiosos etc.

Por fim, é provável que a produção do período silencioso constitua o momento adjetivo do road movie brasileiro, que avança daí por diante rumo ao cinema sonoro, chegando à fase substantiva - eis uma hipótese - na década de 1960, com filmes como Os cafajestes (Ruy Guerra, 1962); Piranhas do asfalto (Neville d'Almeida, 1970); Quando o carnaval chegar (Carlos Diegues, 1972); O amuleto de Ogum (Nelson Pereira dos Santos, 1974); Caçada sangrenta (Ozualdo Candeias, 1974); Iracema, uma transa amazônica (Jorge Bodanzky, Orlando Senna, 1974); Mar de rosas (Ana Carolina, 1977); A dama do lotação (Neville d'Almeida, 1978); Ninfas diabólicas (John Doo, 1978); Bye bye Brasil (Carlos Diegues, 1979); A estrada da vida, Milionário e José Rico (Nelson Pereira dos Santos, 1980); e A opção ou as rosas da estrada (Ozualdo Candeias, 1981). São filmes que, embora sejam produzidos no período da ditadura militar, apresentam dimensões diversas de contestação e contracultura, evidenciadas em discursos cinematográficos de oposição à modernização conservadora do milagre econômico brasileiro. São filmes cujos realizadores estão em boa parte vinculados ao Cinema Novo ou ao Cinema Marginal, com interesse em explorar deslocamentos que se dão em locações externas (diferentemente do que ocorre com o cinema de estúdio das gerações anteriores), em estabelecer tensões entre os limites da ficção e do documentário, em discutir a sexualidade como um aspecto que se reitera enquanto questionamento dos conflitos entre sujeitos masculinos e femininos 
e suas conexões com os veículos automotores. Em suma, em termos de filmes de estrada brasileiros, o percurso para a confirmação de tal hipótese ainda é longo, mas o início está dado.

\section{Referências}

ALTMAN, R. Los géneros cinematográficos. Barcelona; Buenos Aires; México: Paidós, 2000.

ARISTÓTELES. Poética. São Paulo: Nova Cultural, 2000 (Os Pensadores, v. 4).

BAUMAN, Z. Modernidade líquida. Rio de Janeiro: Jorge Zahar, 2001. BERNARDET, J.-C. Caminhos de Kiarostami. São Paulo: Companhia das Letras, 2004. Entrevista Marcelo Gomes e Karim Ainouz. 6 maio 2010. Disponível em: <http://jcbernardet.blog.uol.com.br/ arch2010-05-02_2010-05-08.html>. Acesso em: 14 jul. 2011. . Historiografia clássica do cinema brasileiro: metodologia e pedagogia. São Paulo: Annablume, 1995 (Coleção E, 2).

BRANDÃO, A. S. Lands in transit: imag(in)ing (im)mobility in contemporary Latin American cinema. Tese (doutorado). Florianópolis: Universidade Federal de Santa Catarina, 2009.

CANCLINI, N. Culturas híbridas: estratégias para entrar e sair da modernidade. São Paulo: Edusp, 1998. 
COHAN, S.; HARK, I. R. The road movie book. London, New

York: Routledge, 1997.

CORRIGAN, T. A cinema without walls: movies and culture after Vietnam. New Jersey: Rutgers University Press, 1991.

GUNNING, T. "The whole world within reach: travel images without borders". In: COSANDEY, R.; ALBERA, Fr. (Ed.). Cinéma sans frontières 1896-1918: images across borders. Lausanne; Québec: Payot/Nuit Blanche, 1995.

HOMERO. Odisséia. São Paulo: Cultrix, 2006.

KEROUAC, J. On the road - pé na estrada. Porto Alegre: L\&PM, 2004.

LADERMAN, D. Driving visions: exploring the road movie.

Austin: University of Texas Press, 2002.

MOSER, W. "Presentation. Le road movie: um genre issu d'une constellation moderne de locomotion et de médiamotion". In: Le road movie interculturel. Cinémas. Revue d'études cinématographiques. Journal of Film Studies, v. 18, n. 2-3, printemps/spring, 2008.

MUSSER, C. "The travel genre in 1903-1904-moving towards ficcional narrative". In ELSAESSER, T. Early cinema: space, frame, narrative. London: British Film Institute, 1990.

ODIN, R. "Film documentaire, lecture documentarisante". In: ODIN, R.; LYANT, J. C. (Ed.). Cinémas et réalités. Université de Saint-Etienne, 1984.

PAIVA, S. "A propósito do gênero road movie no Brasil: um romance, uma série de TV e um filme de estrada”. Revista Rumores, edição 6, v.1, setembro-dezembro 2009. "Um road movie na rota do sertão-mar". In: MACHADO JR.; SOARES, R. L.; ARAÚJO, L. C. (Org.). Estudos de cinema Socine. São Paulo: Annablume, 2007.

PAIVA, S.; SCHVARZMAN, S. (Org.). Viagem ao cinema silencioso do Brasil. Rio de Janeiro: Azougue, 2011. 
PETERSON, J. World pictures: travelogue films and the lure of the exotic, 1890-1920. Chicago: Departament of English, University of Chicago, 16 nov. 1998.

RAMOS, F. (Org.). História do cinema brasileiro. São Paulo: Art Editora, 1987.

. (Org.). Teoria contemporânea do cinema. Vols. 1 e 2. São Paulo: Senac, 2005.

RAMOS, J. M. O. Cinema, televisão, publicidade: cultura popular de massa no Brasil nos anos 1970-1980. São Paulo: Annablume, 2004.

RODRIGUES, A. K. A viagem no cinema brasileiro: panorama dos road movies dos anos 60, 70, 90 e 2000 no Brasil. Dissertação (mestrado). Campinas: Instituto de Artes da Universidade de Campinas, 2007.

ROSENFELD, A. O teatro épico. São Paulo: Perspectiva, 1997.

SALLES, W. "Cinema, aspirinas e urubus une forma e geografia". Folha de S. Paulo. São Paulo, 27 nov. 2005. Ilustrada, p. E6.

SILVA, D. T. As Viagens de Salles, Solanas e Sarquís: identidade em travessias. Tese (doutorado). São Paulo: Universidade de São Paulo, 2009.

STRECKER, M. Na estrada: o cinema de Walter Salles. São Paulo: Publifolha, 2010.

XAVIER, I. Alegorias do subdesenvolvimento: cinema novo, tropicalismo, cinema marginal. São Paulo: Brasiliense, 1993. . Sertão mar: Glauber Rocha e a estética da fome. São Paulo: Cosac Naify, 2007.

WATSON, S. “The western”. In: SARGEANT, J; WATSON, S. (Ed.). Lost highways - an illustrated history of road movies. London: Creation Books, 1999. 